\title{
Single Stem Cell Positioning on Polylysine and Fibronectin Microarrays
}

\author{
A. Ruiz ${ }^{1}$, M. Zychowicz ${ }^{1,2}$, L. Buzanska ${ }^{1,2}$, D. Mehn ${ }^{1}$, C.A. Mills ${ }^{3}$, E. Martinez ${ }^{3}$, S. Coecke ${ }^{1}$, J. Samitier ${ }^{3,4}$, \\ P. Colpo ${ }^{*}, 1$ and F. Rossi ${ }^{1}$
}

${ }^{1}$ European Commission, Joint Research Centre, Institute for Health and Consumer Protection, TP 203. Via Fermi, 21027 Ispra (VA) Italy

${ }^{2}$ Medical Research Centre, Polish Academy of Sciences, 5 Pawinskiego St., 02-106 Warsaw, Poland ${ }^{3}$ Nanobioengineering group, Institute for Bioengineering of Catalonia (IBEC), Baldiri Reixac 10-12, 08028 Barcelona, Spain; and Networking Research Center on Bioengineering, Biomaterials and Nanomedicine (CIBER-BBN), Spain

${ }^{4}$ Electronics Department, University of Barcelona. C/ Marti i Franques 1, 08028 Barcelona, Spain 
Abstract: Arrays of human umbilical cord blood-neural stem cells have been patterned in high density at single cell resolution. Pre-patterns of adhesive molecules, i.e. fibronectin and poly-Llysine, have been produced on anti-adhesive poly(ethylene) oxide films deposited by plasmaenhanced chemical vapour deposition, which prevents cell adsorption. The structures consisted of adhesive squares and lines with $10 \mu \mathrm{m}$ lateral dimensions, which correspond approximately to the size of one cell nucleus, separated by $10 \mu \mathrm{m}$ anti-adhesive gap. The stem cells cultured on these platforms redistribute their cytoplasm on the permitted areas. Spherical cells were deposited on the square patterns in a single cell mode, while on the lines they spread longitudinally; the extent of elongation being dependent on the specific (fibronectin) or non-specific (poly-L-lysine) attachment biomolecule. The cell patterns were retained up to 12 days, which will be useful for recording statistical data of individual chronic responses to chemical, physical or physiologically relevant stimuli.

Keywords: Micropatterning, single cell, cell adhesion, stem cell, polylysine, fibronectin.

*Address correspondence to this author at the European Commission, Joint Research Centre, Institute for Health and Consumer Protection, TP 203. Via Fermi, 21027 Ispra (VA), Italy; E-mail: pascal.colpo@jrc.it 


\section{INTRODUCTION}

Arrays of single cells provide platforms for single-cell manipulation and interrogation. Such platforms, combined with predictive models, may enhance the comprehension of molecular and cellular level cell processes that will further key discoveries in the anticipation and detection of events related to biotoxicity. Moreover, they may be an enabling tool for systems biology and for high throughput studies of cell signalling pathways, drug screening and drug toxicity [1].

Single-cell analysis is an important tool to gain insight into many biological mechanisms, as it surveys the distribution of each individual cell response under controlled stimulation and avoid losing feedback characteristics as it can happen in multi-cell sensing averaged measurements. Microengineered platforms to isolate, manipulate, challenge and interrogate cells in isolation and in sub-populations will allow quantitative, single-cell and molecular level understanding of cell metabolism, drug toxicity and chemical signalling pathway activation and inhibition $[2,3]$. In some systems, such as tracing intracellular signalling pathways in the innate immune response of cells to a pathogen, single cell resolution is needed for accurate quantification and kinetics [4]. Also, some particular cellular events such as protein phosphorylation are difficult to detect in large populations and a multiplex approach to simultaneously measure phosphorylation states would enhance the efficiency of phosphorylation mechanistic studies of several signalling proteins in signal transduction pathways $[5,6]$. In addition, cell populations are heterogeneous (cells in different life-cycle, response to insults or infection states) and hence, the population-averaged data is the ensemble of responses of individual cells. New methods and tools are required to generate system- level measurements at single-cell resolution.

Experimentation and measurement at single-cell resolution requires platforms that control the cell environment and whose dimensions match cell dimension. Single cell arrays have already been reported to provide the microenvironment for controlled insult/perturbation experiments and for collecting individual cell responses. Cell-based biosensors have been fabricated using two- 
dimensional [7] and three-dimensional [8] platforms for patterning single live bacterial cell arrays. Three-dimensional structures based on microwells and microfluidic channels have been also used in cell-based sensing using yeast cells [9]. Surface functionalization has been used to generate patterns of non-adherent cells through biospecific interactions between a streptavidin patterned surface and biotinylated cells [10]. Three-dimensional microenvironments have been engineered by microfabrication of polystyrene microwells to investigate morphology and functionality of single cells or clusters [11]. Dynamic culture assays have been reported using a microfluidic-based Ushaped dynamic trapping structure that allows both an arrayed culture of individual adherent cells and a dynamic control of fluid perfusion with uniform environments for individual cells [12]. The examples of single cell arrays in the literature report on the promising advantages of such platforms for cell-biology research, drug screening, drug toxicity and tissue engineering.

In this work, we present a culture platform for single cell arrays of neural stem cells derived from human umbilical cord blood and we show that such patterns may induce different biomoleculedependent stem cell developmental response. These platforms may be useful for fundamental studies on stem cell behaviour and for developing stem cell-based in-vitro toxicology assays.

\section{METHODS}

Silicon oxide - coated silicon moulds, for microcontact printing process, were acquired from Amo GmbH (Germany). The moulds were replicated into polydimethylsiloxane (PDMS) (Sylgard 184, Dow Corning, USA) using a 10:1 mixture of elastomer base - curing agent and hardened at $65^{\circ} \mathrm{C}$ for $4 \mathrm{~h}$. The microstructured PDMS were used as stamps for the direct printing of poly-L-lysine and fibronectin on Petri dishes coated with a layer of plasma polymerized polyethylene oxide-like (PEOlike) film deposited by plasma-enhanced chemical vapour deposition [13]. Before inking, the PDMS stamps were ultrasonicated in ethanol for $5 \mathrm{~min}$ and cleaned in mild $\mathrm{O}_{2}$ plasma (200W, $1.2 \mathrm{mtorr}$ ) for 
30 seconds. The PDMS stamps were then inked at room temperature with the inking solutions containing the biomolecule of interest [14]. FITC-labelled poly-L-lysine (PLL) was diluted in carbonate buffer $(100 \mathrm{mM})$ at $25 \mu \mathrm{g} / \mathrm{ml}$ and $\mathrm{pH} 8.4$, while fibronectin was used in a concentration of $42 \mu \mathrm{g} / \mathrm{ml}$ diluted in printing buffer (100 mM acetate (Riedel deHaën), pH 5, 5 mM EDTA (Merck), 0.01\% TritonX 100 (Fluka) and $0.1 \%$ glycerol (Carlo Erba)). The inking time was 15 min for PLL and 45 min for fibronectin; after which the inking solution was removed and the stamps were dried in a $\mathrm{N}_{2}$ stream. The inked stamps were placed in contact with the substrates for 5 and $10 \mathrm{~min}$, for PLL and fibronectin respectively. Before seeding the cells, the patterned surfaces were sterilized in UV light for $15 \mathrm{~min}$.

A neural stem cell line obtained from the non-haematopoietic mononuclear fraction of human umbilical cord blood (HUCB-NSC) [15] was maintained as the mixed adherent/floating culture in Dulbecco's modified Eagle medium (DMEM/F12, Gibco) containing $2 \%$ fetal bovine serum (FBS, Gibco), insulin-transferrin-selenium (ITS,1:100, Gibco), antibiotic-antimycotic solution AAS (1:100, Gibco), at $37{ }^{\circ} \mathrm{C}, 5 \% \mathrm{CO} 2$, and $95 \%$ humidity. HUCB-NSC cultures were propagated every two weeks by trypsinization (Trypsin/EDTA 0,025\%, Gibco) in 1:4 ratio. For the growth on patterned surfaces, the cells were plated at $2.5 \times 10^{4}$ cells $\mathrm{cm}^{-2}$ density. Following overnight adhesion, any non-adherent cells were washed out with culture medium and the medium was changed every two days.

For immunostaining, the cells were fixed for $15 \mathrm{~min}$ in $4 \%$ paraformaldehyde/phosphate buffer saline (PBS). After fixation, the cells were permeabilized in a $1 \%$ TritonX100 in PBS solution for 15 min. A blocking solution, containing $10 \%$ normal goat serum in PBS, was applied for $1 \mathrm{~h}$ at room temperature. The cells were then incubated overnight at $4{ }^{\circ} \mathrm{C}$ with primary antibodies: polyclonal nestin antibody (1:750, Sigma) and further detected for $2 \mathrm{~h}$ at room temperature by secondary goat anti rabbit IgG $\mathrm{H}+\mathrm{L}$ Alexa 546 (Molecular Probes). To visualize the nuclei, cultures were incubated with Hoechst 33342 (1:1000, Molecular Probes) for 20 min. Fluorescent imaging of proteins and 
optical imaging of the cells were carried out using a Zeiss inverted microscope Axiovert 200 equipped with an incubator.

\section{RESULTS AND DISCUSSION}

An easy-to-use technology, microcontact printing, has been used to produce patterns of poly-Llysine and fibronectin on poly(ethylene) oxide passivated films. The arrays consisted of bio-active areas of $10 \mu \mathrm{m}$ lateral dimensions, either squares or lines, spaced by $10 \mu \mathrm{m}$ areas of cell repellent PEO. Figure (1) shows the fluorescence images of the patterns of poly-L-lysine - FITC labelled. Pattern homogeneity was obtained over $0.5 \times 0.5 \mathrm{~cm}^{2}$ areas. The same patterns were produced in fibronectin. Such arrays were patterned to produce platforms for single cell positioning. Overnight attachment of Human Umbilical Cord Blood - Neural Stem Cells (HUCB-NSC) [15] cultured in highdensity conditions showed a clear localisation with a single cell positioned per spot. Figure (2) shows optical images of the cells attached to the PLL and the fibronectin areas in both configurations. The images are recorded after one day of attachment and it is evident form the morphology of cells that they exhibit a different spreading behaviour depending on the type of biomolecule and the pattern design. These cells have affinity to PLL, to which they attach weakly through anionic-cationic interactions and it allows the study of cellular processes in adherent cells attached to a substrate to which they can only attach and not spread. Small population patterns have been also quickly generated on PLL where it is possible to study migration and differentiation processes [16]. The low cell spreading on PLL, together with the background passivation by plasma-PEO, enable obtaining high density arrays of individual cells, as observed in Figure 2a. On the other hand, cell adhesion to fibronectin involves integrin and focal adhesion signalling, which allows advanced cell spreading [17, 18]. The cell packing on fibronectin is limited by adhesion/spreading competition. Upon attachment, the cells readily spread which allows an adherent cell to occupy neighbouring, free fibronectin squares, as shown in the magnified image in the inset of Figure $2 c$, where one cell occupies four neighbouring fibronectin squares (confirmed by nuclei staining). Figure 3 shows the nuclei of the 
high-density array of cells attached to squares of PLL. The nuclei occupy all the adhesive PLL area, thus the cells are constrained to maintain a spherical shape. However, looking at the electron microscopy images (3b) it becomes evident that the cells sense the neighbouring cells and cell membranes of neighbouring cells contact. Even though cell membranes contact, cell migration from one square to the neighbour would be limited due to the high packing density achieved on PLL and the few cell free squares available. Better isolation of the single cell array could be easily obtained by increasing the spacing between cell adhesive adjacent areas; however, this would decrease the density of the cell array. In the line patterns (Figures $2 b, d$ ), the aspect-ratio of the cells was larger for fibronectin, which is in agreement with our previous observations of higher rate of spreading of HUCB-NSC on printed fibronectin (integrin-mediated cell adhesion) as compared to PLL (electrostatic cell attachment) [19]. Figure 4 shows the distribution of cell length after one day of incubation on line patterns of both biomolecules, measured on 100 cells in three different experiments. On PLL, 57 $\%$ of cells had a length between 10 and $40 \mu \mathrm{m}$ and only $17 \%$ were longer than $60 \mu \mathrm{m}$, while in the case of fibronectin $77 \%$ of cells were longer than $60 \mu \mathrm{m}$ and the majority of cells (39\%) had lengths in the $130-200 \mu \mathrm{m}$ range.

The cell patterns could be kept in culture for up to two weeks. Cell stability on fibronectin patterns was higher than for PLL. Cells on fibronectin remain attached longer and were more resistant to the washing procedures (medium change, PBS washings and immunostaining). Figure 5 shows the cells grown for 5 days on PLL and fibronectin square and line patterns. As compared with overnight attachment (Figure 2), the cell density decreased on PLL and increased on fibronectin (Figure 5). Moreover, in the case of the PLL line patterns, the cells underwent shrinking and detachment losing the elongated shape (Figure 5b). Figure 6 shows the optical images of the cells after 12 days of culture on all patterns, taken after cell fixation. Considerable detachment from the PLL squares is evident (Figure 6a) as well as shrinking and detachment on the PLL line patterns (Figure 6b), while on fibronectin (Figures 6c, d) significantly more cells resisted the washing and fixation procedures and the cells grown on the line patterns exhibited good condition and elongated shape morphology. 
Nestin is an intermediate filament protein expressed in neural stem cells during the early stages of development in the central nervous system and was used as marker for non-differentiated, neuraly committed cells. While entering differentiation pathway neural stem cells stop expressing nestin and start expressing proteins characteristic for neurons or astrocytes [20]. Our first immunostaining experiments showed that the PLL functionalization was useful for keeping the cells in a nondifferentiated state, as confirmed by the positive expression of nestin marker by the majority of cells (Figure 7). On the other hand, the cells grown on fibronectin were negative for nestin immunostaining (Figure 8) (absence of red colour in the cytoplasm of the cells), indicating that they are at early stages of neuronal or astrocytic (not shown) development. The PLL $10 \times 10 \mu \mathrm{m}$ square pattern and thus, the spherical cell morphology retained on PLL showed the most homogeneous non-differentiated stem cell populations, whereas the major cell commitment was observed in the line patterns and elongated cell shapes obtained on fibronectin. The level of homogeneity obtained either in the non-differentiated or in the committed cells on the microarrays is promising for statistical studies of single stem cell responses to different chemical environments.

\section{CONCLUSIONS}

Single cell arrays of human neural stem cells have been obtained by printing poly-L-lysine (PLL) and fibronectin on length-scales commensurate with cell size. $10 \times 10 \mu \mathrm{m}$ squares and $10 \mu \mathrm{m}$-wide lines of PLL and fibronectin were patterned on poly (ethylene) oxide by micro contact printing. A high density of spherical, non-differentiated, individual cells was obtained on the PLL squares. Such approach is interesting for integrated cell based sensors and single cell manipulation and interrogation platforms. On fibronectin, cell spreading and commitment was more prominent, on both the square and line configurations. Cells are able to spread and occupy several free fibronectin squares, and fail to achieve the ordered uniform single cell placement obtained with PLL functionalization. However, the fibronectin patterns were better suited than PLL for long-term cell pattern stability and stem cell commitment, especially in the elongated committed cells observed in 
the lines configuration. We believe that the stem cell arrays will be potentially useful for developmental neurotoxicity studies.

\section{ACKNOWLEDGEMENTS}

This project has been financed by the European Commission Joint Research Centre Actions "NanoBiotechnology for Health" and "Validation for Consumer Products". The authors thank the technical support received from Thierry Martin, Giovanni Maselli and Simone Malfara. 


\section{REFERENCES}

1. Voldman, J. Engineered systems for the physical manipulation of single cells. Curr. Opin. Biotechnol., 2006, 17, 532-7.

2. Chiou, P.Y.; Ohta, A.T.; Wu, M.C. Massively parallel manipulation of single cells and microparticles using optical images. Nature, 2005, 436, 370-2.

3. Vajanaphanich, M.; Schultz, C.; Tsien, R.Y.; Traynor-Kaplan, A.E.; Pandol, S.J.; Barret, K.E. Cross-talk between calcium and cAMP-dependent intracellular signalling pathways. J. Clin. Invest., 1995, 96, 386-93.

4. Itoh, Y; Germain, R.N. Single cell analysis reveals regulated hierarchical T cell antigen receptor signalling thresholds and intraclonal heterogeneity for individual cytokine responses of CD4+ T cells. J. Exp. Med., 1997,186, 757-66.

5. Khan, I.M.; Mendoza, S.; Rhyne, P.; Ziman, M.; Tuscano, J.; Eisinger, D.; Kung, H.J.; Luciw, P.A. Multiplex analysis of intracellular signalling pathways in lymphoid cells by microbead suspension arrays. Mol. Cell Proteomics, 2006, 5, 758-68.

6. Schlessinger, J. Novel fluorescent approaches for studying cell signalling in single cells. Nat. Biotechnol., 2000, 18, 262-3.

7. Veiseh, M.; Veiseh, O.; Martin, M.C.; Bertozzi, C.; Zhang, M. Single-cell-based sensors and synchrotron FTIR spectroscopy: a hybrid systems towards bacterial detection. Biosens. Bioelectron., 2007, 23, 253-60.

8. Biran, I.; Rissin, D.M.; Ron, E.Z.; Walt, D.R. Optical imaging fiber-based live bacterial cell array biosensor. Anal. Biochem., 2003, 315, 106-13.

9. Park, M.C.; Hur, J.Y.; Kwon, K.W.; Park, S.H.; Suh, K.Y. Single cell level array of yeast cells in pumpless microfluidic channels induced by receding meniscus. Lab. Chip, 2006, 6, 988- 94.

10. Lee, Z.W.; Lee, K.B.; Hong, J.H.; Kim, J.H.; Choi, I.; Choi, I.S. Single cell array of biotinylated cells using surface functionalization and microcontact printing. Chem. Lett., 2005, 34, 648-9. 
11. Dusseiller, M.R.; Schlaepfer, D.; Koch, M.; Kroschewski, R.; Textor, M. An inverted microcontact printing method on topographically structured polystyrene chips for arrayed micro-3-D culturing of single cells. Biomaterials, 2005, 26, 5917-25.

12. Di Carlo, D.; Wu, L.Y.; Lee, L.P. Dynamic single cell culture array. Lab. Chip, 2006, 6, 1445-9.

13. Brétagnol, F.; Ceriotti, L.; Lejeune, M.; Papadopoulou-Bouraoui, A.; Hasiwa, M.; Gilliland, D.; et al. Functional micropatterned surfaces by combination of plasma polymerization and liftoff processes. Plasma Proc. Pol., 2006, 3, 30-8

14. Bessueille, F.; Pla-Roca, M.; Mills, C.A.; Martinez, E.; Samitier, J.; Errachid, A. Submerged microcontact printing $(\mathrm{S} \mu \mathrm{CP})$ : an unconventional printing technique of thiols using high aspect ratio, elastomeric stamps. Langmuir, 2005, 21,12060-3.

15. Buzanska, L.; Jurga, M.; Stachowiak, E.K.; Stachowiak, M.K.; Domanska-Janik, K. Neural stemlike cell line derived from a nonhematopoietic population of human umbilical cord blood. Stem Cells Dev., 2006, 15, 391-406.

16. Ruiz, A.; Buzanska, L.; Gilliland, D.; Rauscher, H.; Sirghi, L.; Sobanski, T.; Zychowicz, M.; Ceriotti, L.; Bretagnol, F.; Coecke, S.; Colpo, P.; Rossi, F. Micro-stamped surfaces for the patterned growth of neural stem cells. Biomaterials, 2008, 29, 4766-74.

17. Margadant, C.; van Opstal, A.; Boonstra, J. Focal adhesion signalling and actin stress fibers are dispensable for progression through the ongoing cell cycle. J. Cell Sci., 2007, 120, 66-76.

18. Sastry, S.K.; Lakonishok, M.; Wu, S.; Truong, T.Q.; Huttenlocher, A.; Turner, C.E.; Horwitz, A.F. Quantitative changes in integrin and focal adhesion signalling regulate myoblast cell cycle withdrawal. J. Cell Biol., 1999, 144, 1295-309.

19. Buzanska, L.; Ruiz, A.; Zychowicz, M.; Rauscher, H.; Ceriotti, L.; Rossi, F.; Colpo, P.; Domanska-Janik, K.; Coecke, S. Patterned growth and differentiation of human cord bloodderived neural stem cells on bio-functionalise surfaces. Acta Neurobiol. Exp., 2009, accepted. 
Published in Micro and Nanosystems 1 (2009) 50-56

20. Pankratz, M.T.; Li, X.J.; Lavaute, T.M.; Lyons, E.A.; Chen, X.; Zhang, S.C. Directed neural differentiation of human embryonic stem cells via an obligated primitive anterior stage. Stem Cells, 2007, 25(6), 1511-20. 
Figure captions

Figure. (1). Fluorescence microscopy images of PLL patterns of $10 \times 10 \mu \mathrm{m}$ squares (a) and 10 $\mu \mathrm{m}$ wide lines (b).

Figure. (2). Optical microscopy images of HUCB-NSC after one day culturing on PLL (a, b) and fibronectin (c, d) patterns of $10 \times 10 \mu \mathrm{m}$ square $(\mathbf{a}, \mathbf{c})$ and10 $\mu \mathrm{m}$ wide lines $(\mathbf{b}, \mathbf{d})$. Images recorded on live cells.

Figure. (3). Fluorescence microscopy images of cell nuclei on PLL $10 \mu \mathrm{m}$ square patterns, stained with Hoechst 33342 (a) and SEM image of the single stem cell pattern (b). Black dots indicate the position of the $10 \mu \mathrm{m}$-side PLL squares.

Figure. (4). Distribution of cell lengths for HUCB-NSC attached to PLL and fibronectin line patterns after one day of incubation, measured in approx. 100 cells on 3 different experiments.

Figure. (5). Optical microscopy images of HUCB-NSC after 5 days culturing on PLL $(\mathbf{a}, \mathbf{b})$ and fibronectin (c, d) patterns of $10 \times 10 \mu \mathrm{m}$ square $(\mathbf{a}, \mathbf{c})$ and10 $\mu \mathrm{m}$ wide lines (b, d). Images taken on live cells.

Figure. (6). Optical microscopy images of HUCB-NSC after 12 days culturing on PLL $(\mathbf{a}, \mathbf{b})$ and fibronectin (c, d) patterns of $10 \times 10 \mu \mathrm{m}$ square $(\mathbf{a}, \mathbf{c})$ and10 $\mu \mathrm{m}$ wide lines $(\mathbf{b}, \mathbf{d})$. Images taken after cell fixation.

Figure. (7). Fluorescence microscopy images of nestin immunostaining (red) of HUCB-NSC after 7 days culturing on PLL squares (a) and lines (b). Insets show the corresponding bright field images. Cell nuclei (blue) are stained with Hoechst 33342. 
Published in Micro and Nanosystems 1 (2009) 50-56

Figure. (8). Fluorescence microscopy images of nestin immunostaining (red) of HUCB-NSC after 7 days culturing on fibronectin squares (a) and lines (b). Insets show the corresponding bright field images. Cell nuclei (blue) are stained with Hoechst 33342. 
Figure 1

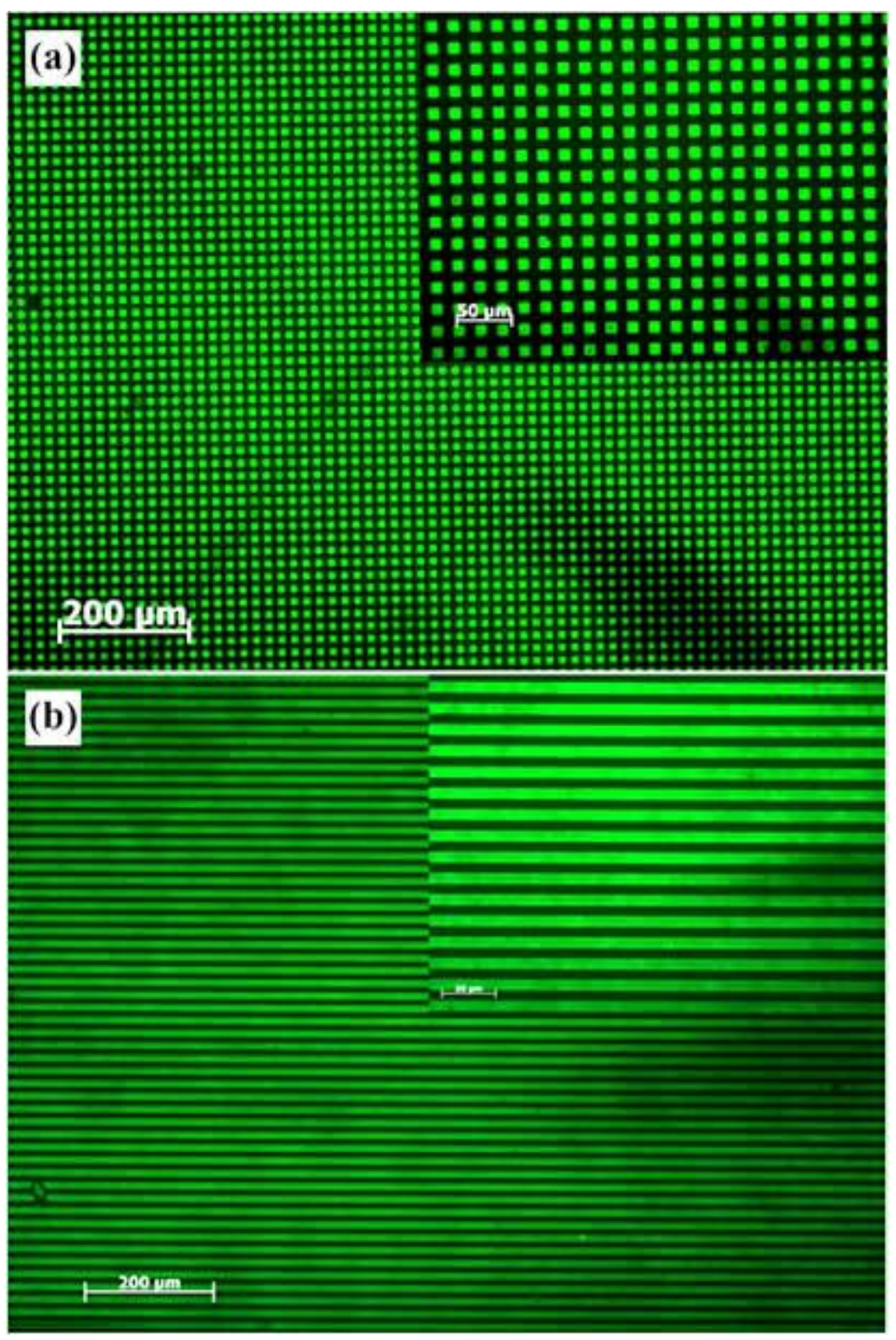


Figure 2
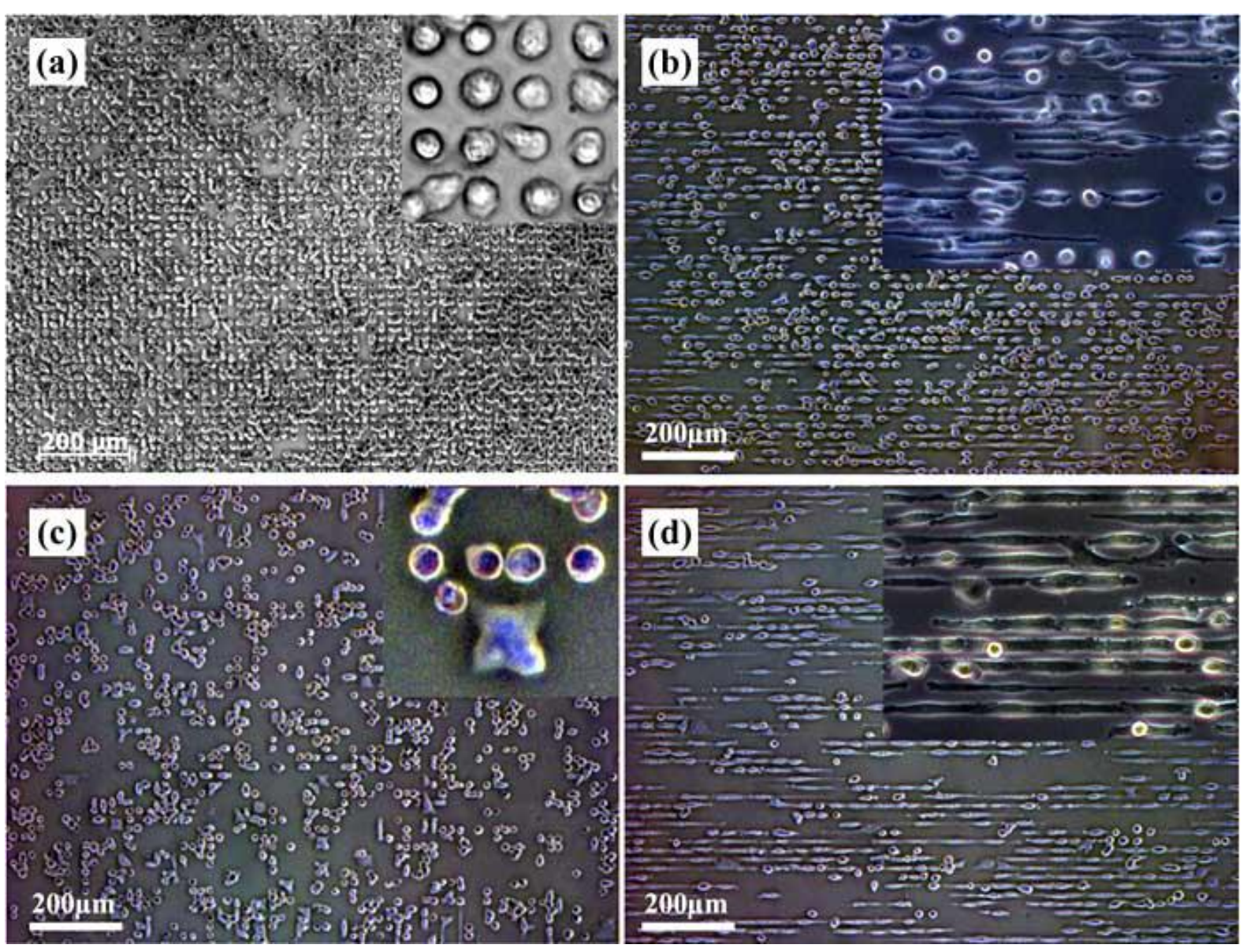
Figure 3
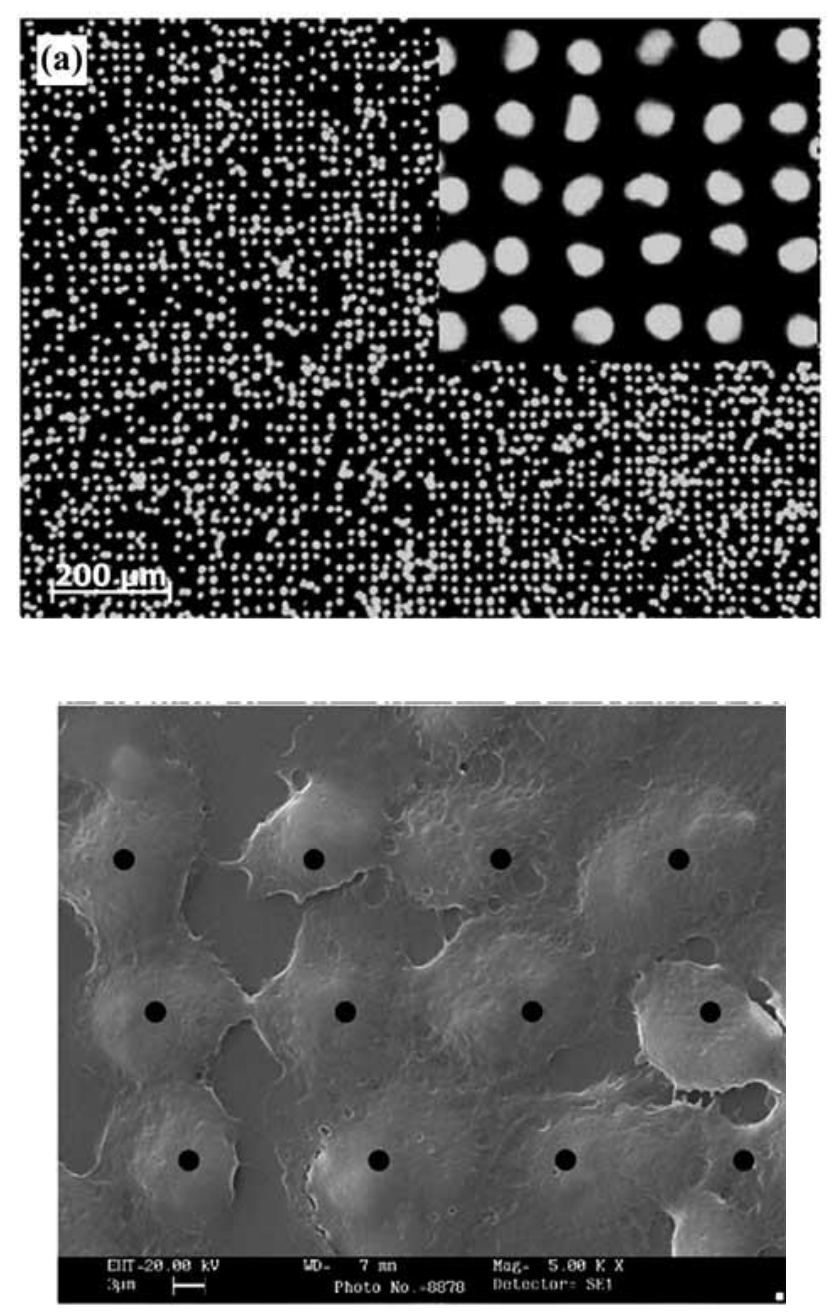
Published in Micro and Nanosystems 1 (2009) 50-56

Figure 4

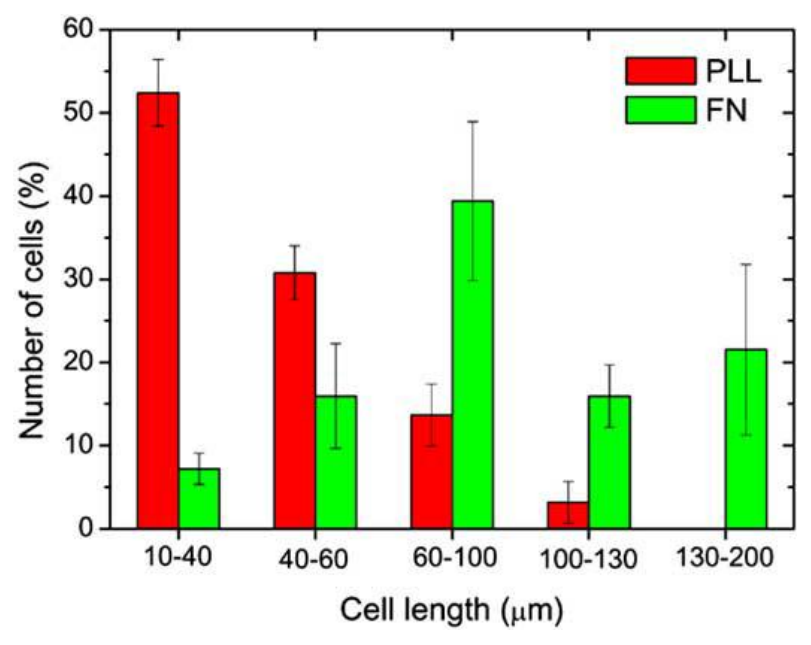


Figure 5
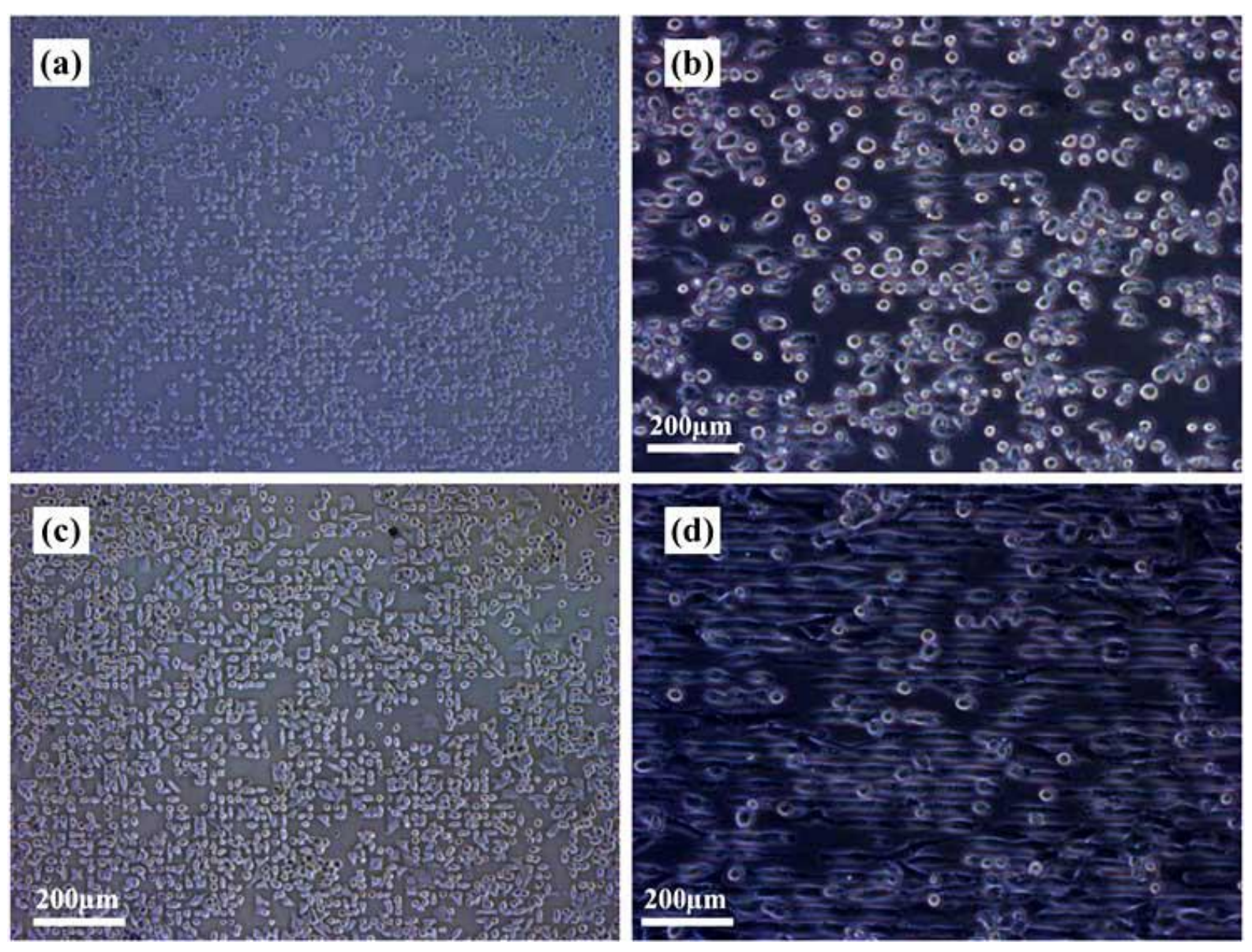
Figure 6

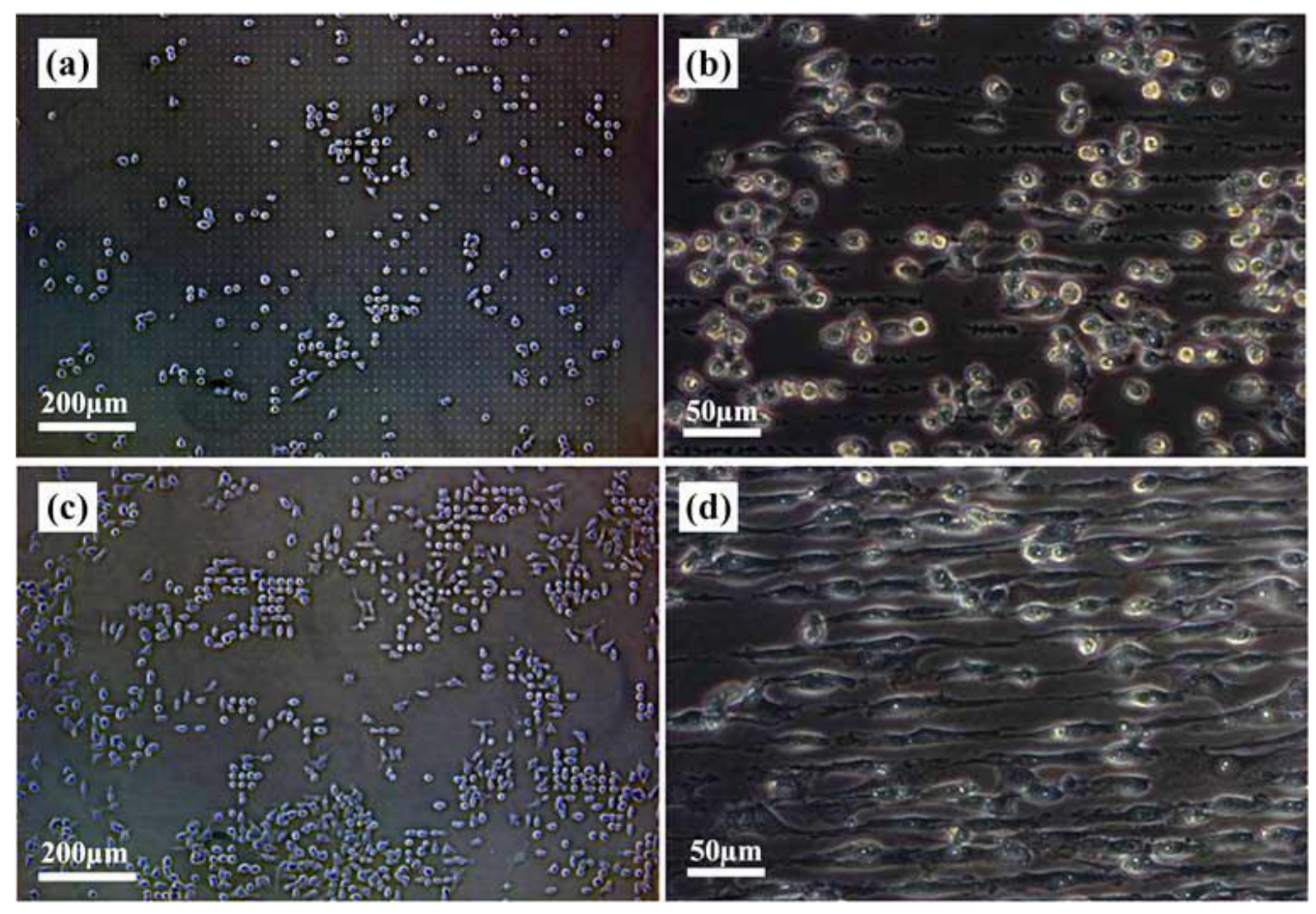


Figure 7
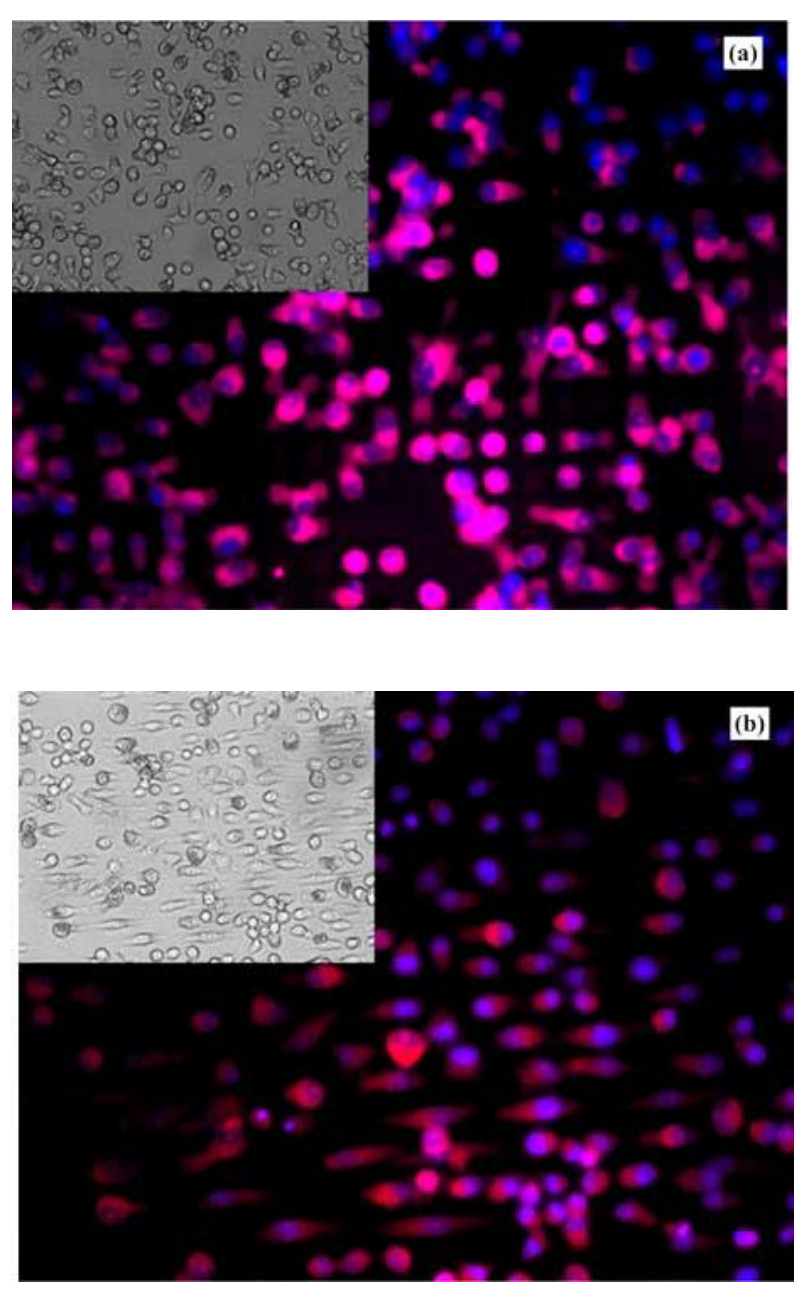
Figure 8

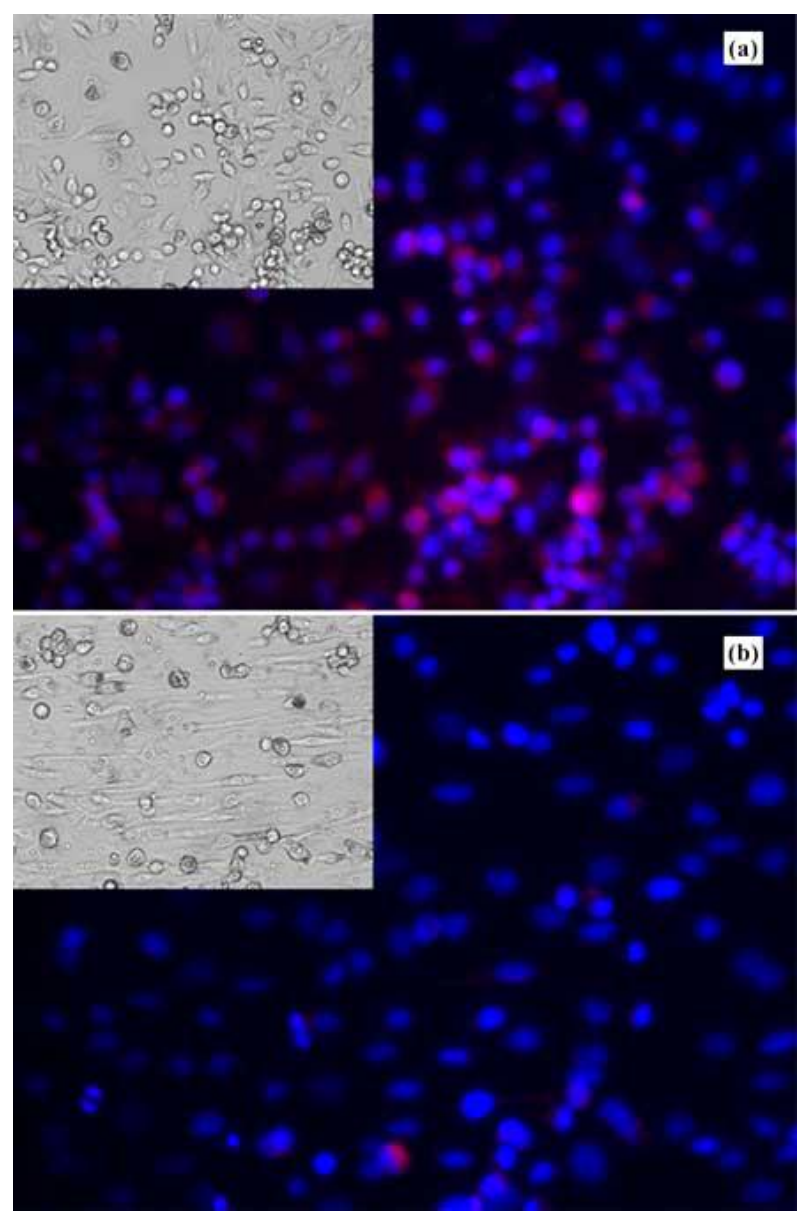

